Chaka could have been written in a European language with the same truly poetic vigour and simplicity which characterize this work and have made it famous.

\title{
L'art congolais au service du culte.
}

Des collaborateurs à cette revue ayant souligné à plusieurs reprises déjà la grande part de l'inspiration religieuse dans les réalisations artistiques indigènes, ont, en présence de la décadence de l'art africain, exprimé leur espoir dans les possibilités de régénération que l'introduction de la religion chrétienne apporte. Aux lecteurs qui voudraient se rendre compte de l'état actuel de la question au Congo, nous signalons le dernier numéro de L'Artisan Liturgique - revue trimestrielle d'art religieux appliqué - consacré exclusivement à ' $L$ 'art congolais au service du culte'.

En tête de cette publication, Mgr Dellepiane, délégué apostolique, rappelant l'attitude traditionnelle de l'église en la matière, attire spécialement l'attention des supérieurs de missions sur l'utilisation de l'art indigène à des fins chrétiennes et leur recommande d'en faire un large usage dans l'édification et la décoration des églises ou chapelles comme dans l'élaboration des objets du culte et de la liturgie. Il salue notamment dans l'inauguration de l'exposition d'art religieux à Léopoldville (18 juin 1936) - la présentation très soignée d'un grand nombre d'illustrations donne quelque idée des pièces qui y étaient exposées - l'aurore de l'art religieux congolais.

Parmi les articles publiés, nous aimons de souligner particulièrement 'L'art indigène et nos missions'. Le délégué apostolique estimant que les efforts tentés pour sauvegarder et christianiser le patrimoine artistique des populations indigènes soulèvent une série de problèmes délicats que les chefs de missions avaient intérêt à aborder et à discuter en commun, avait, en élaborant le programme de la Deuxième Conférence Plénière des Chefs de Missions du Congo Belge et du Ruanda-Urundi, réservé une séance à traiter cette question. Mgr Vanuytven, rapporteur, a introduit le sujet sous le titre indiqué plus haut. L'auteur se montre bien convaincu que 'la religion chrétienne doit produire dans l'art indigène au Congo, ce qu'elle a produit parmi tous les peuples où l'église a fait luire la lumière de la foi. Il s'agit de découvrir l'art vrai indigène, de le conserver, de le protéger et de le perfectionner. L'église désire lui faire parler le langage de la foi; elle charge de ce travail les artistes chrétiens et le clergé accepte avec enthousiasme toutes les coopérations. Le peu d'art que nous voyons autour de nous ne réalise pas, sans doute, l'idéal que nous devons poursuivre et atteindre: cet art n'est pas chrétien, il n'est même pas religieux, mais il peut le devenir. Pour guider son évolution, il faudrait s'abstenir d'imposer des productions d'art religieux européen; surtout qu'il existe une quantité innombrable d'images et de statues et d'objets d'église qui n'ont de religieux que le sujet 
traité, et qui sont absolument sans valeur artistique aucune . . . et qu'il existe des centaines d'églises en Europe dont le type doit être résolument écarté a priori en pays de mission.' Après avoir formulé des directives générales concernant l'utilisation de l'art indigène dans les domaines de l'architecture, de l'ameublement, de l'iconographie et même du théâtre religieux, il arrive à des conclusions pratiques, qu'il est intéressant de relever ici: 'Étant donnée l'utilité indiscutable de respecter autant que faire se peut les manifestations du génie de tous les peuples, même les plus primitifs, (a) il faut que les missions accordent dès à présent une attention sympathique à l'art indigène. (b) Pour cela il faut des spécialistes: le dilettantisme ne suffit pas, il faut des gens compétents, au goût sûr, et ayant une préparation adéquate. Ce n'est que grâce à des missionnaires formés de la sorte qu'on résoudra le problème de l'art indigène, il faut donc souhaiter vivement leur apparition. (c) Il semble qu'une des premières choses à faire ensuite serait de composer un manuel d'art indigène, d'art chrétien, d'art congolais christianisé. Ce manuel devrait rappeler à chaque page qu'un art qui vit de la foi et l'exprime fidèlement est un des plus puissants moyens de conquête que les missionnaires aient à leur disposition pour la plus grande gloire de Dieu. Dès ses premières directives, ce manuel devrait orienter ceux qui le prendraient pour guide à voir avec des yeux d'indigène chrétien et à ne pas copier sans plus les formes traditionnelles et les méthodes de l'Europe, quitte à les exprimer en matériaux indigènes. Le manuel devrait prendre soin de favoriser et de ne pas dénaturer l'éclosion normale des possibilités artistiques indigènes; il devrait provoquer une sympathique et intelligente compréhension de l'art indigène et diffuser celle-ci largement parmi les civilisateurs.' (Communication du PROFESSEUR N. DE CLEENE.)

\section{Mission du Directeur en Afrique Occidentale Frangaise.}

Ainsr que nous l'avons indiqué dans notre précédent numéro, l'un de nos Directeurs, le Professeur H. Labouret, a accompli en Afrique Occidentale Française, pour le compte de son Gouvernement, une mission de cinq mois au cours de laquelle il a visité et étudié les populations du Sénégal, de la Guinée, de la Côte d'Ivoire et du Soudan. Le but principal de ce déplacement était d'effectuer des recherches d'ordre ethnologique sur l'agriculture, le travail, les niveaux de vie et l'alimentation des indigènes dans les territoires observés. Grâce à l'aide de l'administration locale, notre Directeur a pu réunir sur ces importantes questions un matériel très important qu'il va ordonner et présenter dans plusieurs rapports destinés aux Congrès internationaux de l'Exposition de 1937 à Paris.

Le Professeur Labouret a réussi en outre à compléter les collections ethnographiques du Trocadéro et à recueillir une documentation linguistique sur les idiomes en usage dans les pays qu'il a traversés. En particulier il a 